Journal of Computer Science 8 (2): 272-276, 2012

ISSN 1549-3636

(C) 2012 Science Publications

\title{
Supporting Best Practices and Standards for Information Technology Infrastructure Library
}

\author{
Tariq Rahim Soomro and Mihyar Hesson \\ College of Engineering and Information Technology, \\ Al Ain University of Science and Technology, Al Ain, United Arab Emirates, UAE
}

\begin{abstract}
Problem statement: There are several IT best practices and IT standards, which are independently supporting enterprises. Some of them have similarities and other differ from each other. This study discusses these best practices and standards in contrast with ITIL. Approach: CMMI, CobiT, eTOM, ISO 9000, ISO/IEC 17799, Malcolm Baldrige and Six Sigma will be introduces along with ITIL. Results: This study will prove that all these IT based practices and IT standards are useful and helpful when concurrently adopted with ITIL. Conclusion: By adopting the best IT practices and IT standards ITIL will be benefited in IT Service Support and IT Service Delivery areas.
\end{abstract}

Key words: CMMI, CobiT, eTOM, ISO 9000, ISO/IEC 17799, malcolm baldrige, six sigma

\section{INTRODUCTION}

There are number of Information Technology (IT) best practices and IT standards, which are being adapted by several enterprises in recent years; among them there are ITIL, CMMI, CobiT, eTOM, ISO 9000, ISO/IEC 17799, Malcolm Baldrige, Six Sigma and many more. How these can be helpful for Information Technology Infrastructure Library (ITIL)? And how the marriage among them is possible? is actually the focus of this research study. To understand all, we need to understand ITIL first. ITIL is a framework of best practice documents; its main focus is on processes, customer and cost equation (Soomro and Wahba, 2011). In ITIL management, policy and trainings are important factors for success. Specific for IT Service Management ITIL is not perspective and orders the processes in sets. To understand more clearly ITIL; it is important to introduce IT service lifecycle (Quality System Overview, 2011; ITIL-CMM Process Comparison, 2011) as it is organized around a Service Lifecycle: which includes: Service Strategy, Service Design, Service Transition, Service Operation and Continual Service Improvement. The lifecycle starts with Service Strategy- understanding that the IT customers are the service offerings that are required to meet the customers' needs, the IT capabilities and resource that are required to develop these offerings and the requirements for executing successfully. Driven through strategy and throughout the course of delivery and support of the service, IT must always try to assure that cost of delivery is consistent with the value delivered to the customer. Service Design assures that new and changes services are designed effectively to meet customer expectations. The technology and architecture required to meet customer needs cost effectively is an integral part of Service Design. Additionally, processes required to manage services are also part of the design phase. Service management systems and tools that are necessary to adequately monitor and support new or modified services must be considered as well as mechanisms for measuring service levels, technology and process efficiency and effectiveness. Through the Service Transition phase of the lifecycle the design is built, tested and moved into production to assure that the business customer can achieve the desired value. This phase addresses managing changes, controlling the assets and configuration items (underlying components-hardware, software) associated with new and changed systems, service validation and testing and transition planning to assure those users, support personnel and the production environment has been prepared for the release to production. Once transitioned, Service Operation then delivers the service on an ongoing basis, overseeing the daily overall health of the service. This includes managing disruptions to service through rapid restoration of incidents, determining the root cause of problems and detecting trends associated with recurring issues, handling daily routine end user requests and managing service access. Enveloping the Service Lifecycle is Continual Service Improvement (CSI). CSI

Corresponding Author: Tariq Rahim Soomro, College of Engineering and Information Technology,

Al Ain University of Science and Technology, Al Ain, United Arab Emirates, UAE 
offers a mechanism for IT to measure and improve the service levels, the technology and the efficiency and effectiveness or processes used in the overall management of services (Arraj, 2010).

This study will focus on supporting IT based best practices and IT standards, which are independently working for enterprises to ease their complex procedures as well as will support ITIL as a companion. Next "Material and Methods" will introduce these supporting IT best practices and IT standards; Later "Result" will explore how these supporting IT best practices and IT standards will play a vital role if used with ITIL; finally the study will discuss how the marriages of these IT best practices and IT standards with ITIL be beneficial.

\section{MATERIALS AND METHODS}

In today's IT world, organizations are facing number of challenges, to overcome these challenges several IT based best practices and IT based standards are available to ease those organization and fulfill their utmost goals and objectives; among them following are the most prominent and well used IT best practices and IT standards:

The Capability Maturity Model (CMM) was developed by the Software Engineering Institute (SEI) and describes the principles and practices underlying software development process maturity. A Suit of models developed by the SEI includes the software $\mathrm{CMM}$, the System Engineering CMM and the Integrated Product Development CMM have been merged and extended into the CMM Integration (CMMI) (Cater-Steel et al., 2006; Abdullah et al., 2011; Nasir et al., 2008). CMMI is Collection of best practice for software development (ITIL-CMM Process Comparison, 2011); its main focus is on processes, customers and quality of deliverables NSTD Academy, 2001. In CMMI management, policy and trainings are important factors for success (QSR, 2008). CMMI is specific for Software development. CMMI is perspective approach that orders process areas along maturity levels (ITIL-CMM Process Comparison, 2011; QSR, 2008; Wright and Capps, 2008). The Control Objective for Information and related Technology (CobiT) was developed by the International Systems Audit and Control Foundation (ISACF). In 2003, ISACF was renamed as Information Technology Governance Institute (ITGI). CobiT, developed and distributed by ITGI, provides senior management, auditors and users with a set of generally accepted objectives to assist them in developing appropriate IT governance (Cater-Steel et al., 2006). CobiT provides the de facto framework for IT Governance and its main focus is required to achieve governance and control at high level. In CobiT quality criteria, IT processes and IT resources are important factors for success. CobiT can be applied to any organization. It ensures linkage of business and IT plans and track and monitor strategy implementation, project completion, resource usage, process performance and service delivery. CobiT focus efficiently on effectiveness, reliability and integrity (Quality System Overview, 2011; QSR, 2008) Cobit 4.1, 2011.

The enhanced Telecom Operations Map (eTOM), was initiated by Tele-Management Forum (TM Forum), is an industry owned business process framework for the information and communications services industry, primarily telecommunication service providers (Brenner, 2006). eTOM adopted as ITU-T International Recommendation, known in 2004 as M.3050 and it is most widely used and accepted standard for Business Processes in Telecom. It describes full scope of business processes required by a service provider (Enhanced Telecom Operations Map (eTOM), 2011).

ISO 9000 is sponsored by the International Organization for Standardization (ISO) and refers to a set of Quality Management Standards that enable an organization to fulfill the customer's quality (CaterSteel et al., 2006; Nasir et al., 2008). ISO 9000 is generic quality management software emphasizing on auditing and its main focus on processes, customers, quality and audits. In ISO 9000 management responsibility, quality awareness and trainings factors are used for success. It is generally quality system, applicable to any organization. Its management systems, directs and control the organization with regards to its quality. It gives better results with coordination, consistency in processes, increase efficiency and effectiveness (Quality System Overview, 2011; Younes, 2011).

Security is major concerned and there are number of best practice frameworks exist to help organizations assess their security risks, implement appropriate security controls and comply with governance requirements and privacy with information security rules and regulations. The best among them is the most comprehensive approach based on the international information security management standard ISO/IEC 17799 (Saint-Germain, 2005; Wallhoff, 2004).

Baldrige Program's mission is to improve the competitiveness and performance of US based organization and Malcolm Baldrige National Quality Award identifies core values and concepts that must be addressed by an organization wishing to achieve this award (Paulk, 2008). Malcolm Baldrige provides the 
broadest model of total quality management and its main focus is on customers and satisfaction, process management, human resource development, management information and business results. It is broader and deeper than ITIL, CMMI, ISO 9000 and can be applied to any organization. It examines how the organization sets strategic directions and also examines the management, effective use, analysis and improvement of data and information to support key organization processes. It also focus on human resource and process management (Quality System Overview, 2011; ITIL-CMM Process Comparison, 2011).

Six Sigma is in theory defined by (Admin, 2011) as "an applied methodology for improving business and organizational performance. It aims to improve the business process of a company by identifying the sources of errors within the company's processes, dramatically minimizing instances of error to statistical instance of 3.4 defects per million occurrences". Six sigma is high performance approach to sustainable breakthrough improvement. It focuses on waste, rework and error reduction. Also it targets defects, variability through a focus on people, focus on processes, focus on technology, focus on materials and focus on design (Probst and Case, 2009; Nasir et al., 2008).

\section{RESULTS}

Enterprises are currently considering adopting several process improvement frameworks concurrently. Adoption for some IT Managers is a matter of legal compliance, for others, a risk management strategy; a cost saving measurement; or a mean to satisfy customers more effectively (Cater-Steel et al., 2006). It is observed that each model has set of business issues, for which the model is particularly well-suited. To help integrate their improvement strategies, they identify a set of quality genes includes business alignment, strategy planning and execution, governance, training and development, organizational change management, project management, security and threat/risk management, performance management, requirements elicitation and management, relationship management, change and release/configuration management, quality assurance, incident and problem management, process thinking, data-driven process improvement (Paulk, 2008). The supporting IT best practices and IT standards for ITIL are introduced as follows.

ITIL and CMMI: ITIL focuses on IT service management and operations and on the other hand CMMI focuses on software development process improvement. An early version of ITIL CMM is available and framework is devoted to process improvement (Cater-Steel et al., 2006; Nasir et al., 2008). The process areas of ITIL and CMMI have many similarities, for example, organizational performance management, organizational training, configuration management, measurement and analysis and supplier agreement management (Betz, 2011). According to the Gartner survey on ITIL adoption in the Asia Pacific region, it can be assumed that many organizations in Hong Kong, Singapore and Australia are adopting ITIL and CMMI (Cater-Steel et al., 2006). No doubt that CMMI is supporting ITIL (Wright and Capps, 2008).

ITIL and CobiT: The CobiT focuses on IT governance and control and it is weak on process improvement as it is essentially a control framework (Cater-Steel et al., 2006). In fact, 13 out of 34 high-level control objectives are derived directly from the ITIL Service Support and Service Delivery areas (Hill and Turbitt, 2006). The CobiT can play an important role in service desk, incident, problem, configuration, change and release managements for service support management, while service level, financial, capacity, service continuity and availability for service delivery management (Wallhoff, 2004; Hoekstra and Conradie, 2002). According to the Gartner survey many organizations in Hong Kong, Singapore and Australia are adopting ITIL and CobiT (Cater-Steel et al., 2006). The CobiT provides ITIL a mechanism for measuring the capability of the organization that means, people, processes and technology to achieve a successful outcome in meeting the business requirements and for measuring performance. Both ITIL and CobiT provide a valuable combination for helping an organization manage IT from a business perspective, an approach known as Business Service Management (BSM). The CobiT not only provides an effective mechanism for managing and measuring progress in implementing ITIL, but also provides a mechanism for measuring improvement and continual improvement of ITIL. In nut shell, ITIL and CobiT are complementary and can used together to facilitate the transition to BSM (Hill and Turbitt, 2006) and no doubt both are companion.

ITIL and eTOM: The eTOM is the only framework for IT Service Management (ITSM) processes that has experienced considerable adaption in IT industry. ITIL and eTOM have similar aims. Consequently, there are more alignment between eTOM and ITIL, New Generation Operations Systems and Software (NGOSS) systems are just as unlikely to be applicable to ITIL processes, as ITIL tools will be likely to comprehensively support eTOM (Brenner, 2006). The 
eTOM has gradually added strategic, marketing and product lifecycle planning and Enterprise process elements. One of its objectives is to aid the end-to-end automation of information and communications services for business and operations processes by using the holistic eTOM process framework for its entire value chain, including, for example, the service providers, customers, the software/hardware vendors and system integrators. Both eTOM and ITIL are process frameworks and companion to each other (Huang, 2005).

ITIL and ISO 9000: The ISO 9000 focuses on generic quality management system and ISO 9004 provides high level guidance for process improvement (CaterSteel et al., 2006; Nasir et al., 2008). ITIL and ISO 9000 go hand in hand when goal is to achieve quality management in IT service; and their relationship is deeper than just implementation of few standards. ITIL and ISO 9000 provide guidance to enterprises that are willing to implement quality management system for IT, in compliance with the international standards and implementation framework. Both ITIL and ISO 9000 govern the design, development, production and installation of best practices of IT service management (Paulk, 2008). According to the Gartner survey Hong Kong, Singapore and Australia are adopting ITIL and ISO 9000 (Cater-Steel et al., 2006). ISO 9000 is supporting quality companion of ITIL.

ITIL and ISO/IEC 17799: Both ITIL and ISO/IEC 17799 will provide enterprises with a strong toolkit to enable delivery of high quality IT services. ISO/IEC 17799 provides information to parties responsible for implementing information security within an enterprise. It can be seen as a basis for developing security standards and management practices within an enterprise to improve reliability on information security in inter-organizational relationships. ISO/IEC 17799 help ITIL in service desk, incident, problem, configuration, change and release managements as well as service level agreement, finance management for IT service, capacity, IT service continuity and availability managements (Wallhoff, 2004; Hoekstra and Conradie, 2002). ITIL and ISO/IEC 17799 are complementary and can be used together. ITIL can be used to improve general IT processes and controls and ISO/IEC 17799 can be used to improve security controls and processes (Saint-Germain, 2005). ITIL is strong in IT processes, but limited in security and system development, on the other hand ISO/IEC 17799 is strong in security controls, but does not say how does process flow and both have no contradiction or overlapping (Hoekstra and Conradie, 2002) and both are natural companion to each others.

ITIL and Malcomlm Baldrige: The core values and concepts of Malcolm Baldrige are embodies in seven categories (Paulk, 2008). Malcolm Baldrige provides the broadest model of a total quality management system. It is less concerned with identifying specific details of a given process. It can be used by any enterprise and it is high level holistic model for improving the quality of entire enterprise. The approach is self improvement towards top performance focusing on 7 key areas, such that: leadership, strategic planning; customer and market focus; measurement, analysis and knowledge management; workforce focus; process management; and results (Quality System Overview, 2011; ITIL-CMM Process Comparison, 2011; Paulk, 2008). No doubt Malcolm Baldrige is another quality companion of ITIL.

ITIL and Six Sigma: Six Sigma is a proven method for process optimization that enterprises are attributing much success to in recent years (Nasir et al., 2008). For enterprises adopting ITIL best practices, Six Sigma brings four essential benefits, which includes: process optimization/continuous improvement; measuring quality of service and process improvement; focus on service improvement on areas that will have the maximum payback; and provides techniques that measures quality, isolates problems and facilities process improvement changes. Six Sigma can be applied to any business activity from which measurements can be taken and it is obvious that the Six Sigma methodology brings considerable value to ITIL. In particular, with the help of Six Sigma ITIL has great impact (Young, 2004) and it is great companion of ITIL.

\section{DISCUSSION}

This study has described IT based best practices and IT standards, which have been adopted successfully with ITIL and this marriage proves that ITIL should deliver the benefits, which includes, IT Service Support and IT Service Delivery along with but not limited to improve customer satisfaction; increased competence of IT staff; increased IT staff retention; reduced cost of training; reduce cost/incident; closely aligned to commercial business service and products and many more. This research highlights the marriage of concurrent adoption of best practices and standards with ITIL only, but in future, marriage of these IT best practices and IT standards among each other can be explore. 


\section{REFERENCES}

Abdullah, R., A.M. Talib and E.K. Misran, 2011. Agent technology application strategies in personal and team software process environment. Am. J. Econ. Bus. Admin., 3: 347-351. DOI: 10.3844/ajebasp.2011.347.351

Admin, 2011. What is six sigma theory.

Arraj, V., 2010. ITIL $^{\circledR}$ : The Basics. Compliance Process Partners, LLC., APM Group Limited.

Betz, C.T., 2011. ITIL ${ }^{\circledR}$, COBIT $^{\circledR}$ and CMMI $^{\circledR}$ : Ongoing confusion of process and function. BPTrends.

Brenner, M., 2006. Classifying ITIL processes, a taxonomy under tool support aspects. Proceedings of the 1st IEEE/IFIP International Workshop on Business-Driven IT Management, Apr. 3-7, IEEE Xplore Press, Munich, pp: 19-28. DOI: 10.1109/BDIM.2006.1649207

Cater-Steel, A., W.G. Tan and M. Toleman, 2006, Challenge of adopting multiple process improvement frameworks. Proceedings of the 14th European Conference on Information Systems, June, 12-14, Goteborg, Sweden.

Enhanced Telecom Operations Map (eTOM), 2003. The business process framework for the information and communications services industry. TeleManagement Forum.

Hill, P. and K. Turbitt, 2006. Combine ITIL and COBIT to meet business challenges. BMC Software.

Hoekstra, A. and N. Conradie, 2002. CobiT, ITIL and ISO17799 how to use them in conjunction. PWC.

Huang, J., 2005. eTom and ITIL: Should you be Bilingual as an IT outsourcing service provider? BP Trends.
ITIL-CMM Process Comparison, 2011. Pink elephant process maturity model comparison. PINK.

Nasir, M.H.N.M., R. Ahmad and N.H. Hassan, 2008, Resistance factors in the implementation of software process improvement project in Malaysia. J. Comput. Sci., 4: 211-219. DOI: 10.3844/jcssp.2008.211.219

Paulk, M.C., 2008. A taxonomy for improvement frameworks. World congress for software quality, bethesda, MD.

Probst, J. and G. Case, 2009. Integrating six sigma and ITIL ${ }^{\circledR}$ for continual service improvement. Best Management Practice, for Project, Programme, Risk and Service Management, OGC.

QSR, 2008. Six Sigma Iso 9001 And Baldrige.

Quality System Overview, 2011. ITIL/ISO/CMM and Malcolm Baldridge. Pink Elephant North America.

Saint-Germain, R., 2005, Information security management best practice based on ISO/IEC 17799. Inform. Manage. J., 60-66.

Soomro, T.R. and H.Y. Wahba, 2011. Role of Information technology infrastructure library in data warehouses. Am. J. Applied Sci., 8: 13841387. DOI: $10.3844 /$ ajassp.2011.1384.1387

Wallhoff, J., 2004. Combining ITIL with COBIT and ISO/IEC 17799:2000. Scillani Information AB.

Wright, M.K. and C.J. Capps, 2008. Information technology customer service: "Best practices" processes for operations. J. Applied Bus. Res., 24.

Younes, T.M., 2011. GM Quality Assurance (FCI). Understanding ISO9000, Scribd Inc.

Young, T., 2004. Optimizing ITIL service delivery-an overview of Six Sigma and its role in ITIL. Proxima Technology. 